\section{International Scientific Journal Theoretical \& Applied Science}

p-ISSN: 2308-4944 (print) $\quad$ e-ISSN: 2409-0085 (online)

Year: 2017 Issue: $01 \quad$ Volume: 45

Published: $30.01 .2017 \quad$ http://T-Science.org
Oleksandr V. Stovpets $\mathrm{PhD}$ in Philosophy, Doctoral applicant, Philosophy, Sociology \& Sociocultural activities management department, South Ukrainian National Pedagogical University named after K. D. Ushynsky, associate professor of Faculty of Law, Odessa National Maritime University http://orcid.org/0000-0001-8001-4223 a.stovpets@gmail.com

SECTION 30. Philosophy.

\title{
POSTMODERNITY AS THE MOST PROBABLE SOCIO-CULTURAL CONTEXT OF INTELLECTUAL PROPERTY INSTITUTION'S DEVELOPMENT
}

\begin{abstract}
The main subject of this scientific research paper is a post-modern perspective for contemporary culture development, including a specific philosophic vision, distinctive features of mass culture of this era, as well as all its attributes, visible signs and outward manifestations. In a large extent Postmodernity is considered as a socio-cultural, philosophical-historical conception for the world's perception in the post-industrial era, when phenomenon as information, virtualization, reintegration, NBIC-convergence, cultural globalization etc. occur a deep transformation of the previous ideology (i.e. Modernity).

But it's hardly possible to explore, to enlighten, to comprehend the Postmodernity phenomenon without understanding the adjacent (and also extremely controversial) cultural movement as "postmodernism" is. It appears in a few semantic variations. Firstly, it's a certain cultural trend that combines structurally similar phenomena in a global scope of social life and culture, beginning from the second half of the XX century, since the mankind had known two world wars with all their catastrophic consequences, and then came the general disappointment in many "rational values" (so-called "metanarratives crash").

The intellectual elite in different societies has focused on the search for new grounds for the construction of a new ideology. But here we have at least two problems. On the one hand, there has appeared understanding it's not so easy to find as equally significant and consolidating ideas, as the former global sociocultural project (i.e. Modernity) had suggested. On the other hand, the information factor is indicated on the world cultural \& historical horizon since 1970s, when information becomes crucial point, changing the face of human civilization, lifestyle, ideology, values, and an attitude towards many institutions (including the Intellectual property).

In order to comprehend all that has happened in such a short historical period it was necessary to use an alternate philosophy. Thus, probably so-called post-nonclassical type of philosophy was arising, taking into service interdisciplinarity, deconstruction and some other instruments. But this philosophy still did not answer the questions as follows: what is that - the "postmodern culture"? does it have its own grounds, its own content and values? or whether is it based entirely on borrowed artifacts of previous cultural epochs, on using citation, or unbelievable hybrids, or simulacra, or "words games", or other "intellectual tricks"? or all that mentioned are essential elements in the process of a new cultural reality formation?

Perhaps this study will take the social philosophy a little closer to the answers. Anyway, for us the quest for answers to designated questions is a necessary process. Because at present we obviously do not have other more productive technologies in the research of "Postmodernity" as the most probable socio-cultural context for the development of Intellectual Property institution.
\end{abstract}

Key words: Intellectual property, society, Postmodernity, postmodernism, culture, post-nonclassical philosophy.

Language: Russian

Citation: Stovpets OV (2017) POSTMODERNITY AS THE MOST PROBABLE SOCIO-CULTURAL CONTEXT OF INTELLECTUAL PROPERTY INSTITUTION'S DEVELOPMENT. ISJ Theoretical \& Applied Science, 01 (45): 145-152.

Soi: http://s-o-i.org/1.1/TAS-01-45-28 Doi: crossef https://dx.doi.org/10.15863/TAS.2017.01.45.28

\section{ПОСТМОДЕРН КАК НАИБОЛЕЕ ВЕРОЯТНЫЙ СОЦИОКУЛЬТУРНЫЙ КОНТЕКСТ РАЗВИТИЯ ИНСТИТУТА ИНТЕЛЛЕКТУАЛЬНОЙ СОБСТВЕННОСТИ}


Аннотация: Главным предметом исследования данной статьи является постмодерн как перспективное, нарождающееся состояние культуры, включающее в себя своеобразную философскую позицию, а также массовую культуру этой эпохи, и все её атрибуты и внешние проявления. В значительной степени постмодерн рассматривается как сочиокультурная, философско-историческая концеепия восприятия мира в эпоху постиндустриализма, информации, виртуализаџии, реинтеграџии, NBIC-конвергенц̧ии, глобализации культуры и глубинной трансформации прежней (модерной) идеологии.

Но исследовать, познать, осмыслить феномен постмодерна едва ли возможно без понимания смежного (и не менее противоречивого) явления - постмодернизма. Он видится нами в нескольких семантических вариаџиях. Прежде всего, как некий культурный тренд, объединяющий структурно сходные явления в мировой общественной жизни и культуре начиная со второй половинь ХХ века, когда человечество уже познало две мировые войны со всеми их катастрофическими моментами, после чего наступило всеобщее разочарование во многих "рациональных иченностях" (т.н. крах метанарративов).

Интеллектуальная элита в разных обществах озадачилась поиском новых оснований для строительства новой идеологии. И здесь возникли, как минимум, две проблемы. С одной стороны, найти столь же значительные и консолидирующие идеи, какие предлагал прежний глобальный социокультурный проект - модерн - оказалось не так уж легко. С другой стороны, на культурно-исторический горизонт выходит информационный фактор, который с 1970-х предстаёт в принципиально новом свете и меняет облик человеческой циивилизации, образ жизни, идеологию, отношение ко многим иченностям (включая интеллектуальную собственность).

Для осмысления всего происшедшего за столь непродолжительный исторический период была необходима иная философия. Так, вероятно, и возникает т.н. постнеклассический тип философствования, берущий на вооружение междисциилинарность, деконструкцию и ряд иных инструментов. Но данный тип философствования до сих пор не дал ответов на вопросы: что есть "постмодерная культура"? имеет ли она свои собственнье основания, собственное содержание и иенности? или же она строится исключительно на заимствовании артефактов прежсни культурных эпох, на циттировании, на немыслимых ранее гибридах, на симулякрах, на "игре словами" и прочих "интеллектуальных уловках"? или же всё это необходимые элементы процесса становления новой культурной реальности?

Возможно, данное исследование хоть немного приблизит социильную философию к ответам на эти вопросы. Так или иначе, для нас поиск ответов на обозначенные вопросы является необходимым проиессом. Поскольку ныне мы не располагаем иными, более продуктивными технологиями в исследовании Постмодерна как вероятного соцчикультурного контекста для развития института интеллектуальной собственности.

Ключевые слова: интеллектуальная собственность, общество, постмодерн, постмодернизм, культура, постнеклассическая философия.

\section{Introduction}

Эпоха постмодерна, приближающаяся постепенно (и пока ближе всего подошедшая к западной цивилизации), опровергает казавшиеся ещё недавно незыблемыми постулаты о том, что традиция исчерпала себя, и что искусство должно искать другую форму. Постмодернизм - как одна из современных тенденций в творчестве и мышлении - демонстрирует эклектику любых форм традиции, ортодоксии и авангарда. В рамках данной статьи будут рассмотрены некоторые примеры такого заимствования в творчестве, которое (среди прочих видов социокультурной активности) является одним из главных источников происхождения объектов интеллектуальной собственности.

\section{Materials and Methods}

Далеко не все теоретики постмодернизма проявляют благодушное отношение к заимствованиям и конструктивистским новациям в культуре. Так, Ж. Бодрийяр оценивает современное состояние культуры как «состояние симуляции, в котором мы обречены переигрывать все сценарии именно потому, что они уже были однажды разыграны, всё равно - реально или потенциально... Мы живём среди бесчисленных репродукций идеалов, фантазий, образов и мечтаний, оригиналы которых остались позади нас... Исчезла идея прогресса, но прогресс продолжается. Пропала идея богатства, когда-то успешно оправдывавшая производство, но, как видим, само производство продолжается, и с ещё большей активностью, нежели прежде. В политической сфере - идея политики исчезла, но продолжается политическая игра» [1].

Цитирование, симуляция, ре-апроприация всё это не просто термины современного искусства, но его сущность. Ж. Бодрийяр, реинтерпретируя марксистское понятие «надстройка», ввёл понятие «гиперреальность».

Основа гиперреальности - симуляция. Атрибутами гиперреальности являются симулякры - семиотические единицы, знаки, не имеющие означаемого объекта в реальности; воображаемые копии, которые в реальности не имеют оригинала. Симулякры формируются в общественном сознании посредством СМИ и 
являются важным конструктивным элементом виртуальной реальности, часто не зависящей от подлинной реальности и произвольно конструирующей смысл тех или иных событий. По сути, они являются новой разновидностью мифа, однако, в отличие от классического мифа, складываются не стихийно, а в результате направленного информационного воздействия на массовое сознание. Например, с целью сформировать необходимое общественное мнение.

Особую ценность симулякр, как инструмент воздействия, имеет в международной геополитике. Например, кто бомбит гражданские объекты и мирное население в Алеппо? Здесь предлагаются, как минимум, три версии «правды»: антиправительственные силы, включая террористов всех мастей; российско-сирийская коалиция; силы НАТО. И для поддержания каждой из этих версий используются различные симулякры (как то смонтированные имитации авиаударов по гражданским объектам, с последующим распространением в масс-медиа, или неправдивые интервью «очевидцев», часто заявляющих о взаимоисключающих «фактах» корреспондентам разных СМИ).

Ж. Бодрийяр развил учение о трёх порядках симулякров: копии, функциональные аналоги и собственно симулякры. К третьему порядку симулякров он относил все современные феномены, включая деньги, общественное мнение и моду. Они функционируют по принципу символического обмена. Современную же эпоху Ж. Бодрийяр называет «эрой гиперреальности», когда надстройка определяет базис, когда труд не производит, а социализирует, когда представительные органы власти никого не представляют. Современному обществу он приписывает чувство утраты реальности. Последним бастионом реальности становится смерть.

Смерть современного искусства для Ж. Бодрийяра происходит не как конец искусства вообще, а как смерть творческой сущности искусства, его неспособность создавать новое $u$ оригинальное, но как бесконечное самоповторение форм искусство продолжает существовать [2]. Анализ идей данного философа представляется важным для лучшего понимания нынешнего состояния творчества. Ведь оно лежит в основе функционирования всего института интеллектуальной собственности, который неизбежно сталкивается с реалиями грядущего постмодерна.

В целом же, концепция Ж. Бодрийяра основывается на утверждении о необратимой порочности всей западной культуры. Он высказывает апокалиптический взгляд на перспективы искусства: став производным от современных технологий, искусство безвозвратно потеряло связь с реальностью, стало независимой от реальности структурой, перестало быть «подлинным», копируя свои собственные произведения и создавая копии копий, копии без оригиналов, становясь извращённой формой некогда подлинного искусства.

На несколько иных аспектах постмодерной реальности фокусируется Ж.-Ф. Лиотар. Он трактует постмодернизм как способ утверждения возможности так называемого «хэппенинга» в философии, искусстве, литературе, политике. Хэппенинг (англ. happening) - форма современного искусства, представляющая собой действия, события или ситуации, происходящие при участии художника, но не контролируемые им полностью. Хэппенинг обычно включает в себя импровизацию и не имеет, в отличие от перформанса, чёткого сценария. Одна из задач хэппенинга - преодоление границ между художником и зрителем.

В отличие от многих своих современников, Ж.-Ф. Лиотар не разделяет мнения о резком обособлении постмодернизма от модернизма. Он считает, что весьма неудачна периодизация в формах «пост-», поскольку это привносит путаницу и затемняет понимание природы того или иного феномена. Поэтому мыслитель предлагает вообще отказаться от использования приставки «пост-», и для обозначения процессов пересмотра и редактирования предшествующего периода ввести термин «редактируемый модерн». Он считает указанный термин более приемлемым, чем «постмодерн» или «постмодернизм», так как устраняется возможность рассматривать постмодерн как историческую антитезу модерну. Постмодернизм, убеждён Ж.-Ф. Лиотар, уже имплицитно присутствует в самом модерне. Поэтому постмодернизм - это не конец модернизма, не новая эпоха, а модернизм в стадии очередного обновления. Настоящей же антитезой модерна является вовсе не постмодерн, а классика (традиционализм). Модерн содержит «обещание» преодоления себя самого, после чего возможно будет констатировать конец этой эпохи, и датировать начало следующей [3].

В одной из своих работ [4] Ж.-Ф. Лиотар определяет постмодерн как «крах метанарративов» (кризис великих проектов). В качестве метанарративов эпохи модерна он называет такие основные идеи, организующие модерную культуру, как всеобщее равенство и свобода, прогресс, рационализм, гуманизм и прочие идеалы Просвещения. Постмодерн (по Ж.-Ф. Лиотару) олицетворяет собой недоверие в отношении всех подобных метанарративов, утративших свою легитимирующую силу, которая посредством «социальной мифологии» 
некогда поддерживала функционирование всех механизмов управления обществом.

Философ отмечает, что после заката «эпохи больших нарраций» с характерным для неё жёстким «дискурсом легитимации», который исключал саму возможность игры, теперь существует множество т.н. микро-нарративов, и для их анализа он вводит понятие «языковые игры». Однако лучше всего данный термин, на наш взгляд, поясняет не Ж.-Ф. Лиотар, а Х. Г. Гадамер. По утверждению последнего, «...формы протекания всякого разговора можно описать понятием игры» [5]. Идея языковых игр лежит в самой основе постмодерной концепции «читателя» как источника смысла, поскольку в процессе чтения «все трое» (читатель, текст и автор) являют собою единое и бесконечное поле для «игры письма».

По оценке же Ж. Лиотара, постмодернизм избрал «языковые игры» в качестве своей общей методологической установки: они являются минимальными отношениями для самого существования общества. Приводится такой пример, что даже ребёнок, ещё до своего рождения, хотя бы только вследствие данного ему имени уже помещён (как референт) в историю, повествуемую его окружением, в которую он позднее неизбежно будет должен себя вписать. Более того, «вопрос социальных связей» сам является языковой игрой взаимодействием трёх звеньев: вопрошающего, вопрошаемого и предмета вопрошания, что уже является социальным отношением.

Языковые игры, в силу разнородности их элементов, дают возможность своего учреждения посредством сбора и распределения информации. По мере вхождения общества в эпоху, называемую постиндустриальной, а культуры - в эпоху постмодерна, изменяется и статус знания. Пребывая в форме информационного товара, необходимого для усиления производительной мощи, знание уже является и будет оставаться важнейшей, а может быть, и самой значительной ставкой в мировом соперничестве за власть.

По мере развития постмодерной ситуации становится ясно, что постмодернизм сложно назвать искомым типом сознания для человечества. Скорее, это поиск новых форм отношений человека с миром, новых ценностей и критериев во всех сферах культуры. Постмодернизм несёт в себе не только проблематику исчерпанности культуры, но и проблемы поиска того, что будет дальше, поиска новых смыслов и принципов грядущей культуры.

Вероятно, сила постмодерного мышления именно в признании культурной полифонии, открывающей простор для подлинного диалога, в открытости исторического познания, в освобождении его от догматизма (хотя это же было характерно и для модерна, пришедшего на смену традиционализму). Постмодерн, ввиду его эклектичности, стимулирует интеграцию различных культур. Может быть, это даже поспособствует выработке целостного воззрения на мир. Постмодернизм же можно рассматривать как своего рода пролегомен к постмодерну.

Одной из самых крупных теоретических работ, посвящённых постмодернизму, стала книга Ф. Джеймисона «Постмодернизм, или Логика культуры позднего капитализма» [6]. По мнению исследователя, последние полвека были отмечены «крахом идеологий», и не только марксизма-ленинизма, коммунизма, но и общества «всеобщего благоденствия», «социальной демократии» и др. Это стало усматриваться уже на рубеже 1950-х - 1960-х годов, и связано было, прежде всего, с «угасанием» интенсивного столетнего периода «эпохи модерна», с явным, но постепенным идеологическим и эстетическим отказом от него.

В этой связи импрессионизм и постимпрессионизм в живописи, модернистская школа поэзии, экзистенциализм в философии и культуре, предельные формы изображения в литературе и кино выглядят, по Ф. Джеймисону, как «последнее причудливое цветение модернистского порыва», который растратился и исчерпал себя. Постмодернизм же вбирает в себя всё то, что относится к угасанию высокой культуры: китч и гламур, массовую культуру телесериалов, клипов, телешоу, рекламы, одноразовых голливудских фильмов, популярной современной литературы от стандартных детективов и любовных историй до кровавых ужасов и мистерий. Иными словами, произошло то, что эстетическое производство сегодня встроилось в товарное производство (в этом смысле показательной является массовая истерия вокруг iPhone и других визуальных атрибутов престижа в его современном понимании).

Правомерно, по Ф. Джеймисону, выделить следующие определяющие характеристики постмодернизма: новое отсутствие глубины, находящее своё продолжение как в современной «теории», так и в новой культуре имиджа и симулякрума (поверхностность, эклектичность); последовательное ослабление историчности (фрагментарность сознания); совершенно новые виды базисных эмоциональных состояний, которые Ф. Джеймисон предлагает называть «интенсивностями»; постмодерные мутации на уровне архитектурного пространства (built space); изменение стратегий политического искусства в запутанном мировом пространстве многонационального капитала и новой экономики. По мысли Ф. Джеймисона, произошла фундаментальная мутация как самого предметного мира (ставшего сегодня набором 
текстов и симулякров), так и конфигурации субъекта.

Всё сказанное подводит к характеристике, которую Ф. Джеймисон советует называть «угасанием аффекта» в постмодерной культуре: такие понятия, как тревога и отчуждение, неуместны более в мире постмодернизма. В частности, для исследователя образцовым выражением модернистских тем отчуждения, отсутствия ценностей, одиночества, социального распада и изолированности, служит картина Э. Мунка «Крик» (1893-1910), которая является настоящей программной эмблемой того, что принято называть «веком тревоги». Нынешнее же изменение в динамике «культурной патологии» может быть охарактеризовано как сдвиг, в результате которого модернистское «отчуждение субъекта» замещается его распадом. Этот термин неизбежно напоминает об известной в современной гуманитаристике концепции «смерти субъекта» М. Фуко - конце автономной «буржуазной монады». У Ф. Джеймисона постмодернизм сигнализирует о конце описанной дилеммы, заменяя её новой: конец буржуазного ego предполагает исчезновение психопатологий этого ego (то, что называется «угасанием аффекта»). Но это означает и конец стиля как явления уникального и личного, освобождение от экзистенциальной «тревоги», от всякого рода чувств и эмоций (апатия).

Модернистские стили превращаются в постмодернистские кoдbl, и это превращение сопровождается хаотичным, неупорядоченным поглощением всех стилей прошлого, игрой случайными стилистическими аллюзиями. Здесь, однако, Ф. Джеймисон указывает на необходимость выявить ту степень, в которой модернистское понятие стиля, и сопутствующие ему общественные идеалы художественного и политического авангарда сохраняются или рушатся вместе с этим устаревшим понятием «центрированного» субъекта. Очевидно, что в разных обществах подобные процессы протекают различно. И по количественному соотношению носители идеологии модерна пока что в разы превосходят число носителей постмодерного мышления. Данное соотношение оказывает определяющее влияние на общее восприятие такого социального института, как интеллектуальная собственность. Поэтому на сегодняшний день ещё можно характеризовать отношения в упомянутой сфере как основанные на ценностях эпохи модерна. И любые попытки отрицания либо пересмотра этих «модерных» интеллектуально-правовых ценностей ныне неизбежно порождают социальные конфликты разных масштабов и оттенков.

Но мы сейчас не станем углубляться в юриспруденцию, а сосредоточимся на обзоре отдельных трендов развития института интеллектуальной собственности в сфере искусства. Ведь произведения последнего - не только продукты творческой деятельности, но одновременно и объекты интеллектуальной собственности (в подавляющем большинстве случаев).

Для демонстрации того, как проявляются в контексте постмодерного концепта ранее упомянутые признаки, такие как «деканонизация», «маргинальность», «ирония», интересно рассмотреть некоторые тенденции в развитии музыки. Они вполне наглядно отражают специфику нынешней культурной ситуации, в частности, тот факт, что философия постмодерна поставила под сомнение саму правомерность и приемлемость распределения культуры на «высокую» и «низкую».

Яркий пример - фестивали «нестандартной классики». Сейчас они очень популярны в Европе, а теперь увидеть подобное действо можно было и в Киеве. Странное зрелище: концерт классической музыки, во время которого музыканты общаются между собой, чихают, кашляют, едят и даже приглашают зрителей на сцену, чтобы те им подыграли. Причем музыкальным инструментом здесь может быть и печатная машинка, и детская писклявая игрушка. Для неподготовленного зрителя это может показаться абсурдом. Но такая импровизация - в русле постмодернизма. Случайность, маргинальность, даже провокативность, уменьшение роли композитора в музыкальной композиции (которое может выражаться в использовании случайности как композиторской техники) становится нередким явлением даже в академической музыке постмодерной эпохи.

Предтечей появления т.н. алеаторической (случайной) музыки можно назвать одного из пионеров электронной музыки, американского композитора Д. Кейджа. Он декларирует отказ от тотального детерминизма композитора и ставит в основу музыкальной композиции случайность. Имеет место игра - и не только на инструментах, но и метафизическая, принимающая иной раз гротескные формы. В ряде «произведений» Д. Кейдж полностью «отстраняет» себя от композиторского процесса. Так, выйдя к публике в 1952 году, в т.н. «пьесе 4’33» участники его ансамбля не извлекают ни единого звука из своих инструментов, а сама «композиция» длительностью целых 4 минуты 33 секунды содержит исключительно окружающий шум. По мнению самого Д. Кейджа, так стираются границы между исполнителем и аудиторией, а также между музыкантами и окружающей средой [7].

Для нас же, учитывая специфику данного исследования, в отношении приведенного 
примера важно отметить следующее: если для эпохи модерна характерна выраженность границы «искусство - неискусство», то постмодернизм позволяет себе применение принципа «искусством может называться всё». Стоит акцентировать внимание, что здесь действующее законодательство об охране интеллектуальной собственности в Украине и за её пределами, как ни странно, вписывается в постмодерные реалии: объектом авторского права (произведением) и смежных прав (исполнением) могут быть признаны любые формы творчества, независимо от их завершённости, социальной востребованности и оценки, духовной и эстетической ценности, иных социокультурных характеристик. Единственным требованием для признания в качестве творческого либо интеллектуального результата законодательство выдвигает в отношении всех произведений признак новизны (оригинальности) и какой-либо возможной воспринимаемости (объективной формы).

Для иллюстрации других постмодерных признаков - «коллажности», эклектичности, гибридизации, цитирований и вариаций (ссылок на уже существующие произведения) - в истории музыки существуют очень разные, и вполне достойные примеры, «благородные» с точки зрения традиционного восприятия. Так, в 15-й симфонии Д. Шостаковича содержатся цитаты из «Вильгельма Телля» Д. Россини и «Кольца нибелунга» Р. Вагнера.

Рок-музыка содержит неисчислимое множество примеров музыкального коллажа, с цитированием наиболее выразительных фрагментов из произведений классики (хотя многие рок-композиторы отказываются от термина «коллаж», мотивируя это тем, что ссылки являются не случайными, а знаковыми в концепции композиционного целого). Известная музыкальная тема «В пещере горного короля» Э. Грига вдохновила на создание одноимённых композиций и музыкальных вариаций такие разные рок-группы, как The Who (1967), Electric Light Orchestra (1973), Savatage (1987), Rainbow (1994), Apocalyptica (2000), Butterfly Temple (2002) и других.

Ещё один яркий пример: композиция группы Accept «Metal Heart» (1985) содержит во вступлении обработку музыкальной темы из «Славянского марша» П. Чайковского, а в своей сольной партии - фрагмент пьесы «К Элизе» Л. ван Бетховена. Есть немало рок-коллективов, которые пошли ещё дальше: они создали целые концептуальные альбомы на основе цитирования классических мотивов. Так, прогрессив-метал группа Therion в 2012 году выпустила студийный альбом «Les Fleurs du Mal» - не имеющий аналогов микс жанра symphonic metal c французским шансоном, обильно сопровождаемый женским оперным сопрано, целым оркестром, и конечно же, с явной отсылкой к одноимённому скандальному сборнику стихов «Цветы зла», выпущенному в XIX веке Ш. Бодлером.

Последний приведенный выше пример (с Therion) вновь подтверждает тезис о том, что заимствование, практикуемое современным (во многом - постмодерным) искусством, так или иначе может быть связано с возрождением и с реинтерпретацией достижений премодерна (т.е. традиционализма). С одной стороны, создаются новые произведения (и все они претендуют на статус объектов права интеллектуальной собственности). Но если «посмотреть в корень», можно констатировать, что основой многих из Hoвыx произведений являются достижения npoшльх эпох, культурные артефакты которых уже давно перешли в разряд общественного достояния (public domain). Но это никак не умаляет их культурного значения и, нередко, вдохновляющей роли для творчества новых поколений. С учётом такой «связи времён» и «творческой переклички» ныне здравствующих и давно ушедших в историю авторов - сводить любое произведение исключительно $к$ праву интеллектуальной собственности, тем более абсолютизировать данное право, - видится не таким уж незыблемым постулатом. Хотя не секрет, что крупнейшие правообладатели «копирайта» прилагают максимальные усилия, чтобы защитить свою монополию на знания и новые достижения как на уровне глобальных конвенций, так и на локальных законодательных уровнях.

Но мы вновь отклонились от взятого курса на исследование постмодерных явлений, и оказались во власти размышлений о не вполне справедливом механизме «копирайта». Поэтому вернёмся к проблематике постмодернизма.

А. Солженицын оценивал постмодернизм как «опасное культурное явление», которое «размонтировало современный мир до состояния кладбища». Он предлагал чётко делить всё искусство на реалистическое и авангард. Последний им рассматривался как проявление разрушительной эстетики, во многом подготовившей революции и войны $\mathrm{XX}$ в. Современная культура постмодернизма, по мнению А. Солженицына, является продолжением авангарда и не имеет реальной ценности, т.к. замыкается на себе, а у творца в таком случае нет ответственности ни перед кем. В отказе же от традиции заложена враждебность ко всякой духовности [8, с. 259]. Можно отчасти согласиться с приведенным утверждением, что в постмодерной культуре действительно сильные позиции занимают такие её атрибуты, как 
нигилизм, деканонизация, десакрализация, реминисценция, ирония и т.д. Вместе с тем, постмодерная культура обращена к человеку, свободному в своём выборе, а значит, возникает новое пространство для любых творческих исканий. По крайней мере, гипотетически.

Хотя есть и другие мнения о природе постмодернизма. Ещё более бескомпромиссные, чем у А. Солженицына, но не менее интересные. Кто-то утверждает, что это псевдокультура, что «постмодернизм - это культура без собственного содержания, использующая в качестве строительного материала какие угодно наработки прошлого, и своей синтетичностью и искусственностью более всего напоминающая соцреализм» [9; 10]. Иные [11; 12; 13] полагают, что постмодернизм вообще не имеет реальных теоретических оснований, а представляет собой «софистику и интеллектуальные уловки».

А началась эта беспрецедентно жёсткая критика в адрес философии постмодернизма с того, что профессор физики А. Сокал из НьюЙоркского университета написал в 1994 г. сатирическую статью под названием «Преступая границы: к вопросу о трансформативной герменевтике квантовой гравитации» (англ. «Transgressing the Boundaries: Towards a Transformative Hermeneutics of Quantum Gravity»). В своей статье А. Сокал, обсуждая некоторые из текущих проблем математики и физики, в абсолютно ироничном ключе «переносит» их следствия в сферу культуры, философии и политики в расчёте привлечь внимание модных академических философов, подвергающих сомнению притязания науки на объективность. Статья представляла собой искусно написанную пародию на современные философские междисциплинарные исследования и, конечно же, была лишена какого-либо реального научного (физического) смысла. А. Сокал послал статью в академический журнал «Social Text», который, несмотря на то, что он является рецензируемым (peer-reviewed), опубликовал её.

Несколько позже эта «научная афера» была раскрыта самим А. Сокалом в статье в другом журнале, «Lingua Franca», где он объяснил, что его статья в «Social Text» была «обильно приправлена абсурдом» и, по его мнению, была принята к публикации только потому, что хорошо выглядела для редакторов издания с точки зрения выдержанности в популярном ныне постмодернистском ключе. Еще позже была издана целая книга [11], которая «разоблачала» стиль рассуждений многих современных философов, включая «столпов» французского постмодернизма - Ж. Лакана, Ж. Делёза, Ю. Кристевой, Ф. Гваттари и других.

Упомянутая книга с восторгом была встречена отдельными учёными-скептиками.
Достаточно сказать, что рецензия на эту книгу получила название «Postmodernism disrobed» (есть и её русскоязычный перевод под красноречивым названием «Разоблачение постмодернизма»). В рецензии [12], в частности, утверждается, что «лингвистические игры», нечёткое мышление (которое допускает условность любых ценностей) и бесконечная рекомбинация всего написанного, в течение длительного времени подпитывавшие постмодернизм, стали в итоге благодатной почвой для расцвета «эстетствующего иррационализма» и распространения огромного количества текстов сомнительной научной ценности, однако с явной претензией на научность.

Р. Докинз, известный английский биологэволюционист и популяризатор науки, а также родоначальник так называемой «меметики» (междисциплинарной концепции о передаче культурной информации) вообще довольно резко высказывается в адрес постмодернистской философии: «...Представьте себе, что есть самозваный интеллектуал, которому нечего сказать в науке, но изо всех сил он стремится стать известным учёным, собрать вокруг себя благодарных учеников и добиться того, чтобы студенты по всему миру уважительно мазали жёлтым маркером страницы его трудов. Какой литературный стиль он изберёт? Не простой и ясный, конечно же, потому что ясность в таком случае сразу же разоблачила бы полную бессодержательность... Например, физика - на самом деле сложный и глубокий предмет, поэтому физикам стоит усердно работать ещё и над тем, чтобы сделать свой язык как можно проще (но не проще, чем можно, как подчёркивал А. Эйнштейн). Представители же гуманитаристики страдают от того, что П. Медавар назвал «завистью к физике». Они хотят, чтобы за ними также признавали глубину мысли, хотя в действительности их предметы часто являются довольно поверхностными. Поэтому «лирикам» и приходится перегружать свой профессиональный язык слишком уж специфической лексикой в стремлении компенсировать описанное «неравенство» с «физиками»...» [13].

\section{Conclusions}

Постмодерная философия оценивается поразному. Как можно было удостовериться, нередко её представители подвергаются развёрнутой и основательной критике, не лишённой объективности. И всё же, несмотря на остроумие и меткость упомянутых работ, отрицать само существование постмодерной философии бессмысленно. 
Исходным пунктом в объяснении смысла данного непростого понятия будет утверждение, что постмодернизм - это мировоззрение, выражающее основные тенденции, установки и ориентиры общества, достигшего некоего определённого уровня развития. Причём, оно не сводится к какому-либо единому учению или теории. Скорее его надо рассматривать как широкий спектр различных подходов и точек зрения, касающихся разных областей знания, но, несмотря на это, имеющих нечто общее, объединяющее.

Наиболее очевидные черты философии постмодернизма - это ирония, бесконечное цитирование и заимствование, а также т.н. деконструкция реальности (которая на самом деле может оказаться всего лишь игрой словами, манипуляцией знаками). Разумеется, постмодернизм (социокультурный тренд) не тождественен постмодерну (грядущей эпохе, о вероятности прихода которой, судя по различным нынешним предпосылкам, говорят многие исследователи). Но эти два понятия, несомненно, родственны и взаимосвязаны. Институт интеллектуальной собственности уже сейчас испытывает воздействие постмодерной идеологии, очертания которой просматриваются в ходе анализа вышеупомянутых тенденций в культурном развитии цивилизации.

\section{References:}

1. Baudrillard, Jean. (1981) Simuliakry $i$ simulaciya [Simulacres et simulation]; transl. by A. Kachalov. - Moscow: Postum, 2015. 238 p. (rus).

2. Baudrillard, Jean. (1976) Simvolicheskiy obmen i smert' [Symbolic Exchange and Death]; transl. and introduct. by S. Zenkin. - Moscow: Dobrosvet, 2011. - 392 p. (rus).

3. Lyotard, Jean-François. (1994) Zametki o smyslakh "post-" [Notes on the senses of "post"]; transl. by A. Garadzhi. - Moscow, 1994. № 1, pp. 54-66. (rus).

4. Lyotard, Jean-François. (1979) La condition postmoderne [The Postmodern Condition]; transl. by G. Bennington and B. Massumi; foreword by Fredric Jameson. - Minneapolis: University of Minnesota Press, 1984. 110 p. (eng).

5. Gadamer, Hans-Georg. (2006) Igra iskusstva [Game of the Art]; transl. by A. Yaveckiy // Problems of Philosophy. - 2006. - № 8, pp. 164-168. (rus).

6. Jameson, Fredric. (1991) Postmodernism, or The cultural logic of late capitalism. - Durham: Duke University Press, 1991. - 438 p. (eng).

7. Gann, Kyle. (2010) No Such Thing as Silence: John Cage's 4'33". - New Haven [Conn.]: Yale University Press, 2010. - 272 p. (eng).
8. Markova M (1997) Kultura postmodernizma $i$ russkije dissidenty [The culture of Postmodernism and Russian dissidents] // Metamorphoses of History. Scientific almanac. - № 1. - 1997, pp. 256-260. (rus).

9. Epstein, Mikhail N. (1999) Informacionniy vzryv $i$ travma postmodernizma [Information explosion and the trauma of postmodernism] // Zvezda. - 1999. - № 11, pp. 216-227. (rus).

10. Epstein, Mikhail N. (2004) Znak probela. $O$ budushem gumanitarnykh nauk [Sign of a gap. The future of humanities]. - Moscow: New Literary Review, 2004. - 864 p. (rus).

11. Sokal, Alan D.; Bricmont, Jean. (1998) Intellektualniye ulovki: kritika sovremennoy filosofii postmoderna [Fashionable nonsense: postmodern intellectuals' abuse of science]; transl. by A. Kostikova, D. Kralechkin; foreword by S. Kapica. - Moscow: Dom intellektualnoy knigi, 2002. - 248 p. (rus).

12. Dawkins, Richard. (1998) Postmodernism disrobed // Nature, vol. 394, 9 July 1998, pp. 141-143. (rus).

13. Dawkins, Richard. (2013) Kapellan diavola. Razmyshleniya o nadezhde, lzhi, nauke i lyubvi [A Devil's Chaplain: Reflections on Hope, Lies, Science and Love]; transl. by P. Petrov. Moscow: Corpus, ACT, 2013. - 416 p. (rus). 